\title{
A Five-Stage DEA Model for Technological Innovation Efficiency of China's Strategic Emerging Industries, Considering Environmental Factors and Statistical Errors
}

\author{
Gang Zeng ${ }^{1,3}$, Haixia Guo ${ }^{2 *}$, Chengxuan Geng ${ }^{3}$ \\ ${ }^{1}$ School of Economics and Management, Civil Aviation University of China, Tianjin, 300300, P.R. China \\ ${ }^{2}$ School of Foreign Languages and Literature, Tianjin University, Tianjin, 300350, P.R. China \\ ${ }^{3}$ School of Economics and Management, Nanjing University of Aeronautics and Astronautics, \\ Nanjing, Jiangsu, 211106, P.R. China
}

Received: 30 January 2020

Accepted: 2 June 2020

\begin{abstract}
The development of strategic emerging industries is important for China's Economic structure optimization and low-carbon economy. The purpose of this paper is to scientifically evaluate the technological innovation efficiency of strategic emerging industries. A five-stage data envelopment analysis (DEA) model was proposed. The model combines the super slack-based-measure (SBM) -Tobit-Super SBM and bootstrap DEA, improving the classical DEA model as well as the popular four-stage DEA model method. The purpose of this study is to design a scientific and accurate method to evaluate the efficiency of technological innovation, considering the impact of environmental factors and statistical errors on the efficiency value.

Input indicators were considered from the perspectives of capital, labour, and land, and output indicators were considered from the perspectives of science, technology, and the economy. Environmental factors such as regional economic level, labour market, and financial support were excluded. The empirical results show that: (1) the five-stage DEA model eliminates environmental interference and avoids the impact of statistical noise to reduce outliers; (2) after eliminating environmental interference and statistical noise, the technological innovation efficiency of strategic emerging industries in the Eastern, Central, and Western regions of China show a "U-shaped" fluctuation, with the highest in the Eastern region (0.57), followed by the Western region (0.56), and the Central region (0.53); and (3) environmental factors have a significant impact on the innovation activities of China's strategic emerging industries.
\end{abstract}

Keywords: strategic emerging industries, technological innovation efficiency, five stages, DEA model, environmental factors, statistical noise

*e-mail: haixia.guo@tju.edu.cn 


\section{Introduction}

China's rapid economic growth has brought increasingly serious problems of environmental pollution and resource shortage, which are caused by the inappropriate economic development model. In order to speed up the building of a resource-conserving and environment-friendly society, the Chinese government has actively implemented the basic state policy of conserving resources and protecting the environment. On the one hand, in order to further implement "made in China 2025" and strengthen environmental regulations, enterprises that are not environmentally friendly in traditional industries such as electricity, steel, building materials, non-ferrous metals, chemical industry, petroleum and petrochemical, shipping, coal, printing and dyeing, paper making, leather making, dye, coking and electroplating will be phased out. On the other hand, we will vigorously promote the development of strategic emerging industries such as new generation of information technology, high-end equipment, new materials, biology, new energy, new energy vehicles, energy conservation and environmental protection, and digital creativity, with the goal of making these green and low-carbon industries leading industries. Fig. 1 reports that during the $13^{\text {th }}$ five-year plan period, China has set targets for ammonia-nitrogen emissions. By 2020, the provinces of Hebei, Shanxi, Zhejiang, Henan, Beijing and Tianjin will have cut emissions by more than $16.1 \%$, while the six provinces of Sichuan, Hebei, Guangdong, Shandong, Hunan and Jiangsu will have cut emissions by more than 1.25 thousand tons.

Therefore, in order to save energy and reduce emissions to promote the transformation and upgrading of traditional industrial structure, we must vigorously strategic emerging industries. However, the strategic emerging industries are characterized by high technology content, large capital input and uncertain risks. Compared with developed countries, China's strategic emerging industries suffer from low technological innovation efficiency and unbalanced regional development. It is of great significance to the sustainable and healthy development of regional economy to study the technological innovation efficiency of China's strategic emerging industries to reduce resource waste and increase enterprise innovation output.

Research on the method of technological innovation efficiency is one of the hot topics in China and the world. In 1972, AFRIAT first put forward the concept of technological innovation efficiency, emphasizing the technical efficiency of R\&D innovation activities. [1]At present, there are mainly two kinds of methods to study the efficiency of technological innovation: one is the parameter estimation method based on the stochastic frontier production function (SFA) proposed by Aigner et al. (1977). [2] For example, Song G. et al. selected sample data of SMEs from 30 provinces in China, and measured their technical efficiency with stochastic frontier analysis method and found that Chinese SMEs are not technically efficient, but they have a growing trend. [3] Wang $X$. et al. based on nuclear density estimation and SFA model, analyzed the dynamic evolution trend of innovation efficiency and decomposition index and the influencing factors of innovation efficiency in Chinese universities from 2011 to 2015. [4] The other is a non-parametric estimation method represented by data envelopment method (DEA) proposed by Charne C. et al. [5] For example, Li H. et al. used a slack-based measure data envelopment analysis (SBM-DEA) model and a panel threshold model to study the impact mechanisms of environmental regulation on technological innovation. [6] Shen N. et al. measure energy efficiency in China using the three-stage data envelopment analysis (DEA) model and then tests the convergence of China's energy efficiency. [7] $\mathrm{Su} \mathrm{K}$. et al. analyzed the ecoefficiency of industrial enterprises by using the superefficiency DEA model and spatial metrology. [8] Liu Y. et al. calculated the ecological efficiency of urban

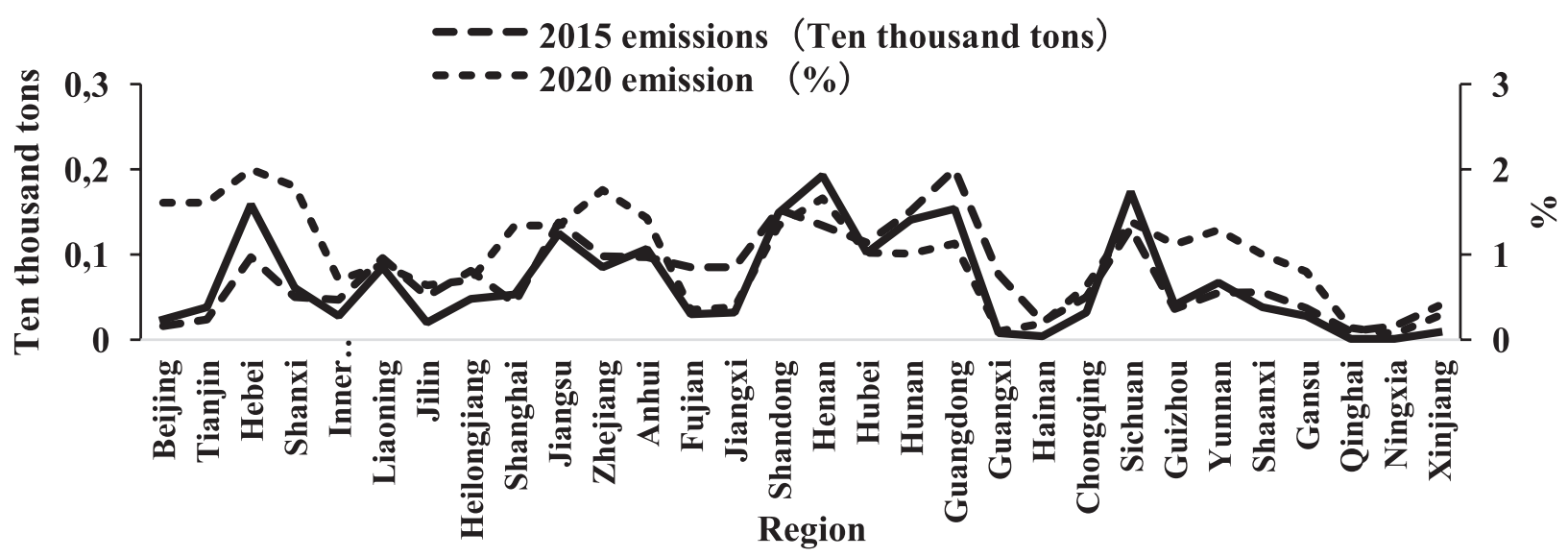

Fig. 1. A total emission control plan for ammonia nitrogen in all regions during the $13^{\text {th }}$ five-year plan period.

Note: due to lack of data, Tibet is not included, Source: comprehensive work plan for energy conservation and emission reduction during the $13^{\text {th }}$ five-year plan period 
agglomeration in the Yangtze River economic belt from 2005 to 2015 with non-radial, non-angled DEA model with undesired output [9]. Teirlinck P. et al. examine the determinants of firm level output efficiency of R\&D. And their focus is on the space industry in Belgium, a highly geographically concentrated industry. [10] Shin J. et al. analyzed the effect of RMEC on innovation efficiency considering both innovation inputs and outputs. Also, they utilized data of 388 manufacturing enterprises in Korea, and performed data envelopment analysis and tobit regression analysis. [11] Lee J. et al focus on the collaboration efficiency that arises from the research and development efforts of small and mediumsized enterprises (SMEs).They examine the stepwise effect of collaboration for the phases of innovation and confirmed that collaboration had different effects on R\&D and commercialization. [12]

This paper focuses on the relevant methods of DEA model. Since the parameters of the model do not need to be estimated in advance, DEA model has the advantage of avoiding evaluation errors caused by nonobjective factors. At the same time, the model results can not only compare the effectiveness of different efficiency but also provide the improvement direction of inefficient unit. Undeniably, DEA model evaluation also has some limitations. According to Charnes A., DEA model requires homogeneous external environment between decision making units; otherwise, different decisions making units with the same efficiency value cannot be compared. In addition, it is difficult to identify measurement errors due to non-random mode, so the data of input and output of the model must be accurate and measurable. The DEA model does not consider random errors caused by data, measurement and luck.

The external environment of strategic emerging industries, including factors such as the economy, culture, and policy, vary regionally in China. If the classical DEA model is used to evaluate the efficiency of technological innovation, different industries will be considered in homogeneous environments, or the influence of the operating environment on the production frontier will not be considered. However, both these approaches are inconsistent with the basic assumptions of DEA model. Some operating environments promote the technological innovation efficiency of production units, while others impede it. The influence of operating environments therefore needs to be taken into account when making decisions. It has become an important research trend in DEA model expansion in recent years to eliminate or separate the various impacts of environmental factors on the production efficiency of sample units.

Literature review shows that most of the studies use the multi-stage DEA modeling analysis framework to study the efficiency of technological innovation, including the DEA model from one stage to four stages. CHEN Y. et al used the one-stage DEA model of VRS radial to conduct a comparative study on technological innovation efficiency of different types of large and medium-sized industrial enterprises. [13] Bao Y. et al established a two-stage DEA model for the technology R\&D stage and achievement transformation stage of product innovation, and conducted an empirical analysis on the innovation efficiency of China's flatpanel display industry and three flat-panel display enterprises including BOE, Infovision Optoelectronics (IVO) and Tianma data. [14] Qu G. et al. investigated the technological innovation efficiency of China-listed companies on the basis of controlling environmental factors based on the three-stage DEA model. The research shows that the overall technological innovation efficiency of China-listed companies is low, with the average value of less than 0.7. [15] Liao M. et al. took panel data of 30 provincial administrative regions in China from 2002 to 2012 as samples, and applied DEA model and four-stage DEA model to verify collaborative innovation efficiency of various provinces in China. [16]

Many studies have analysed the impact of environmental factors on efficiency by employing DEA models ranging from one to four stages. The one-stage DEA model, also known as the frontier separation method, groups the samples in advance according to one of the most important characteristics in the operating environment, and considers the impact of multiple environmental factors on the evaluation. However, the sample grouping of this method is prone to statistical errors. The two-stage DEA method is an improvement of the one-stage method. It first uses the classical DEA model to obtain results, and then uses the statistical regression method to eliminate environmental influence. However, this method tends to ignore the production information of excessive input and insufficient output.

In 1999, Fried et al. proposed the three-stage (BCC-SFA-BCC) DEA model, which first calculates the efficiency value using the Banker, Charnes and Cooper's model (BCC) model, then adjusts the input variable by using the SFA model to eliminate environmental factors, and finally re-calculates the efficiency value by using the adjusted input and output statistics. [17] However, the three-stage model truncates input relaxation variables, which easily leads to inconsistent parameter estimation. Subsequently, Fried et al. proposed the fourstage DEA model method. [18] The main difference between this method and the three-stage DEA method is that Tobit regression replaces SFA regression in the second stage to ensure consistent parameter estimation. Nevertheless, the four-stage DEA model still cannot eliminate the impact of random error.

Many studies expand on the four-stage DEA model. Avkiran constructs the SBM-Tobit-SBM model by replacing the BCC model with the SBM model to eliminate the influence of environment. However, this model requires a regression model to predict the maximum and minimum values of the relaxation variate. Chen $\mathrm{K}$. et al. construct the RAM-TobitRAM model by combining the RAM and Tobit model to reduce statistical noise. [19] Fan D. et al. study 
the energy efficiency of Chinese industrial enterprises by combining the four-stage DEA method with the bootstrapped DEA method. [20] Chen C. et al. evaluate agricultural technical efficiency with the fourstage DEA method, and correct deviations with the bootstrapped DEA method. [21] Zhao J. et al. calculate the green efficiency of China's economy in 30 provinces (as well as cities and autonomous regions) in 2016 by using the four-stage DEA model to eliminate the impact of external environmental variables. [22] $\mathrm{Yu} \mathrm{M}$. et al. use the four-stage DEA method to investigate the influence of the external environment on the production efficiency of the new energy vehicle industry. [23]

The research above provides inspiration for this study. The four-stage DEA model proposed by Fried et al. obtains the relaxation variables calculated by the initial DEA model, adjusts the relaxation amount according to the environmental difference of decisionmaking uncertainty (DMU), and then re-adjusts the input or output data and re-calculates the new data to eliminate the influence of environmental factors. However, there are still two significant problems with this model. First, it is impossible to eliminate the interference of statistical noise in the results. Second, the BCC model employed at the first stage has several shortcomings in dealing with technical inefficiencies and endogeneity.

Therefore, this study will further improve the four-stage DEA model to effectively evaluate the technological innovation efficiency of China's strategic emerging industries. The Super-SBM model is introduced to replace the BCC model, and the bootstrapped DEA method is introduced to carry out a repeated self-sampling test on the model to eliminate the influence of statistical noise. Accordingly, a fivestage DEA model is constructed combining the Super SBM-Tobit-Super SBM and the bootstrapped DEA models. The main purpose of this paper is to evaluate the efficiency of technological innovation by building a more scientific and accurate model. By examining the effects of environmental factors and statistical errors on the efficiency of technological innovation, this paper will analyze the different effects of internal and external factors. Finally, the paper puts forward some policy Suggestions to promote the technical efficiency of strategic emerging industries.

\section{Material and Methods}

In this study, the Super-SBM model proposed by Ton is employed to calculate the initial efficiency value at the first stage of the five-stage DEA model, since the Super-SBM model can order the effective decision units by permitting the efficiency value $\theta \geqq 1$. [24-25] The five-stage DEA model is constructed as an improvement of the four-stage DEA model studied and applied in China and abroad [26]. The next section provides more details of the methodology.
Stage one: Calculate initial technology innovation efficiency based on Super-SBM model

The following formula is used for the calculation of China's strategic emerging industries:

$$
\begin{gathered}
\min \theta=k-\frac{1}{m} \sum_{i=1}^{m} \frac{s_{i}^{-}}{x_{i 0}} \\
\text { s.t } 1=k+\frac{1}{s} \sum_{r=1}^{s} \frac{s_{r}^{+}}{y_{r 0}} \\
\mathrm{k} x_{i 0}=\sum_{j=1, j \neq 0}^{n} \lambda_{j} x_{i j}+s_{i}^{-} \\
\mathrm{k} y_{r 0}=\sum_{j=1, j \neq 0}^{n} \lambda_{j} y_{r j} j-s_{r}^{+} \\
A_{j} \geq 0, s_{i}^{-} \geq 0, s_{r}^{+} \geq 0, t>0
\end{gathered}
$$

...where $n$ is the number of samples, $\mathrm{X}=x_{i j}$ is the input vector, $\mathrm{Y}=y_{i j}$ is the output vector, $m$ and $k$ are the categories of input and output, respectively, $\lambda$ is the column vector, and $\theta$ is the target technological innovation efficiency value. In addition, $x_{i 0}(\mathrm{i}=1 \ldots m)$ and $y_{i 0}(r=1 . . k)$ are the elements of $\mathrm{X}$ and Y, respectively, and $s_{i}^{-}$and $s_{r}^{+}$represent the slack variables of input and output, respectively. This model can be used to estimate the technological innovation efficiency of China's strategic emerging industries.

Stage two: Determine the direction of the impact of external environment on efficiency

The Tobit regression model can effectively distinguish the positive and negative influences of the external environment. Tobit first proposed the concept of the Censored Regression Model in 1958. At the same time, the economist A.S. Goldberger first applied the Tobit model in practice. The Tobit model has a very powerful feature in that the regression variables can be either continuous numerical variables or 0-1 type virtual variables, which is very convenient for studying environmental variables in DEA.

In this study, the number of Tobit regression models constructed is $I$. The total relaxation amount of input will be selected as the dependent variable, and external environment variables will be selected as the explanatory variable, where $I$ is the number of input variables. This can be represented by the following formula:

$$
S_{i k}=\alpha_{i}+\beta_{i} Z_{i k}+\mu_{i} \quad i=1,2, \ldots, I, \mathrm{~K}=1,2, \ldots, N
$$

...where $S_{i k}=\left(1-\hat{\theta}_{k}\right) x_{i k}+S_{i k^{-}}$is the $i$-th relaxation variable measured in the first stage; $Z_{i k}$ is the vector of exogenous environmental variables; $\alpha_{i}$ is a constant term; $\beta_{i}$ is the coefficient vector to be evaluated; and $\mu_{i}$ is the error term. 
Stage three: Remove environmental factors and readjust the initial input variables

The corresponding fitting value can be obtained by substituting the relaxation variables of all input factors into formula (2). Using $\hat{S}_{i k}=\alpha_{i}+\beta_{i} Z_{i k}$, the initial variable is adjusted. The formula is as follows:

$$
\begin{gathered}
x_{i k}^{a d j}=x_{i k}+\left[\operatorname{Max}^{k}\left\{\hat{S}_{i k}\right\}-\hat{S}_{i k}\right] \\
\mathrm{i}=1,2, \ldots, \mathrm{I}, \mathrm{k}=1,2, \ldots, \mathrm{N}
\end{gathered}
$$

The purpose of this adjustment is to make the maximum fitting relaxation value $\operatorname{Max}^{k}\left\{\hat{S}_{i k}\right\}$ represent the worst environmental condition.

1) When the environment is least conducive to efficiency, $\operatorname{Max}^{k}\left\{\hat{S}_{i k}\right\}-\hat{S}_{i k}=0$ and the adjusted input $x_{i k}{ }^{a d j}=x_{i k}$, that is, no adjustment is made to the initial input.

2) When the environment is conducive to efficiency, $\operatorname{Max}^{k}\left\{\hat{S}_{i k}\right\}-\hat{S}_{i k}>0$ and the adjusted input $x_{i k}{ }^{a d j}>x_{i k}$, which is equivalent to increasing the initial input. If the output remains constant, the increase in initial input reduces the efficiency value accordingly.

Therefore, the above adjustments can effectively "punish" DMUs with high efficiency due to the good external environment in order to remove the increase in efficiency caused by environmental factors. In the end, all DMUs are compared in the worst possible environment.

\section{Stage four: Re-measure technological innovation efficiency value $\hat{\boldsymbol{\theta}}$}

The adjusted input-output data were substituted into the Super SBM model to obtain the new $\hat{\theta}$ value. This represents the worst environment for the DM,U which is equivalent to the efficiency level achieved by a reduction in input at a percentage of at least $\left(1-\hat{\theta}^{\circ}\right)$.

The four-stage DEA method outlined above effectively "filters" the influence of exogenous environmental variables and realizes the ordering and comparison of effective unit values. In addition, it avoids the classification of environmental variables in advance. However, the effect of statistical noise cannot be eliminated, and there is still some deviation for the obtained efficiency value.

Stage five: Build the bootstrapped random DEA model with environmental and statistical noise removed

DEA model uses the production frontier to estimate the efficiency value of decision making unit. The estimated result is relative efficiency, instead of the absolute "efficiency" concept in the statistical sense. KNIEP A et al. pointed out that the asymptotic distribution of efficiency values of DEA model is usually difficult to determine. Bootstrap method can infer the empirical distribution of DEA model estimates, and then correct the deviation of efficiency estimates and give its confidence interval. [27] The basic concept is: No assumptions are made on the unknown population; on the basis of the original data, the data generation process is simulated by repeated sampling, so that the approximate sample distribution of the original estimator is obtained, and the overall characteristics are further statistically inferred. Therefore, Bootstrap method is introduced in the fifth stage of this paper to modify the above four-stage model values. The model principles and methods are shown in the study of Simar L. et al. [28]. The specific idea is:

1) Use the input-output data with environmental variables excluded as the initial sample of bootstrap DEA, and then substitute them into the Super SBM model to calculate the sample efficiency score $\hat{\theta}^{o}=\left(\hat{\theta}_{1}^{o}, \hat{\theta}_{2}^{o}, \ldots, \hat{\theta}_{N^{0}}\right)$;

2) Repeat the putting-back-sampling method to extract a sample of native bootstrap with size $\mathrm{N}$ from $\hat{\theta}^{\circ}: \hat{\beta}^{0^{*}}=\left(\hat{\beta}_{1 b}{ }^{0^{*}}, \hat{\beta}_{2 b}{ }^{\mathrm{o}^{*}}, \ldots, \hat{\beta}_{N b}{ }^{\mathrm{o}^{*}}\right)$;

3) Smooth the native bootstrap sample to obtain the smooth bootstrap sample $\hat{\theta}^{\circ}: \hat{\beta}^{0^{*}}=\left(\hat{\theta}_{1 b}^{\mathrm{o}^{*}}, \hat{\theta}_{2 b} \mathrm{o}^{*}, \ldots, \hat{\theta}_{N b} \mathrm{o}^{*}\right)$

Among them:

$$
\begin{gathered}
\theta_{\mathrm{kb}}^{0 *}=\bar{\beta}_{\mathrm{b}}^{0 *}+\frac{1}{\sqrt{1+h^{2} / \hat{\sigma}_{\theta^{0}}}}, \bar{\beta}_{\mathrm{b}}^{0 *}=\frac{1}{N} \cdot \sum_{k=1}^{N} \beta_{\mathrm{kb}}^{0 *}, \bar{\theta}_{\mathrm{kb}}^{0 *}= \\
\left\{\begin{array}{c}
\beta_{\mathrm{kb}}^{0 *}+h \varepsilon_{\mathrm{kb}}^{0 *}, \text { if } \beta_{\mathrm{kb}}^{0 *}+h \varepsilon_{\mathrm{kb}}^{0 *} \leq 1 \\
2-\beta_{\mathrm{kb}}^{0 *}-h \varepsilon_{\mathrm{kb}}^{0 *}, \quad \text { otherwise }
\end{array}\right.
\end{gathered}
$$

In the above formula, $\mathrm{h}$ represents the smoothing parameter $\hat{\sigma}_{\theta \circ}$ the standard deviation of $\hat{\theta}^{\circ}$, and $\varepsilon$ the random error.

4) Readjust the indicators, mainly by smoothing the sample $\hat{\theta}^{\mathrm{o}^{*}}=\left(\hat{\theta}_{1 b} \mathrm{o}^{*}, \hat{\theta}_{2 b} \mathrm{o}^{*}, \ldots, \hat{\theta}_{N b}^{\mathrm{o}^{*}}\right)$ according to $\hat{\theta}_{1 b}{ }^{0^{*}}=\left(\hat{\theta}^{\circ} / \theta_{\mathrm{kb}}^{\mathrm{o}^{*}}\right) \cdot x_{k}^{a d j}, k=1,2 \ldots, N$.

5) Calculate the bootstrapped DEA efficiency value of the $j$ th decision making unit $\hat{\theta}_{j b}{ }^{0^{*}}$. The data source is selected from the adjusted input and original output data in step 4).

$\hat{\theta}_{j b}^{o *}=\operatorname{argmin}\left\{\begin{array}{c}\theta \mid y_{j} \leq \sum_{k=1}^{N} \gamma_{k} y_{k}, \theta x_{k}^{a d j} \geq \sum_{k=1}^{N} \gamma_{k} x_{k b}^{o *}, \quad \theta>0 ; \\ \sum_{i=1}^{N} \gamma_{k}=1 ; \gamma_{k} \geq 0, k=1,2, \ldots, N\end{array}\right.$

6) Repeat steps 2-5 for $\mathrm{Q}$ times $(\mathrm{Q}=1000)$, then the statistics obtained by each DMU are:

$$
\left\{\hat{\theta}_{k b}^{o *}, b=1,2 \ldots, Q, \mathrm{k}=1,2, \ldots, \mathrm{j}, \ldots, \mathrm{N}\right\}
$$

7) Test the deviation of the initial value DMU $\hat{\theta}_{k}^{\circ}$ and the adjusted efficiency value $\theta_{k}^{\wedge}$. The specific formula is as follows: 


$$
\begin{gathered}
\operatorname{bi} \hat{a} S_{k}=\frac{1}{B} \cdot \sum_{b=1}^{B} \hat{\theta}_{k b}^{o *}-\hat{\theta}_{k}^{o} \\
\theta^{\Delta}{ }_{k}^{o}=\hat{\theta}_{k}^{o}-\operatorname{bi} \hat{a} S_{k}, \mathrm{k}=1,2, \ldots, \mathrm{N}
\end{gathered}
$$

Through adjustment by the above method, external environmental variables can be effectively eliminated. The four-stage technical efficiency value $\hat{\theta}^{0}$ can be re-calculated afterward. To further reduce the impact of random errors, the estimated value $\theta^{\Delta^{0}}$ , excluding environmental factors and random errorsis finally obtained using the bootstrap model method on the basis of $\hat{\theta}^{0}$.

\section{Research Idea of the Five-Stage DEA Model}

The idea of the five-stage DEA model constructed in this study is shown in Fig. 2.

\section{Selection of Model Variables}

\section{Input Index}

Selecting the appropriate input-output index is key to calculating the technological innovation efficiency of strategic emerging industries. The evaluation indicators of this study make references to the existing research results [29-30]. According to the Cobb-Douglas production function, the factors affecting innovation activities include three categories: capital, labour, and land. As for the investment elements of technological innovation activities, extant research usually considers research and development (R\&D) resources. In this study, three secondary indicators, namely, internal R\&D expenditure (IRDE), technology introduction expenditure (TIE), and domestic technology expenditure (DTE), are selected to measure the capital input of strategic emerging industries.

In addition, the full-time equivalent of $R \& D$ personnel (RDP) accurately reflects the actual workload of innovation activities, and is a more scientific indicator than the number of R\&D personnel selected as the labour input index in some studies. As for the land element measurement of innovation activities in strategic emerging industries, the fixed investment in technological innovation can be used as a reference. Considering that most $R \& D$ activities are realized through specialized R\&D institutions, the number of R\&D institutions (NRDI) is selected as the direct input indicator of innovation activities in this paper.

\section{Output Index}

The output activities of innovation should consider both market-oriented scientific and technological products and actual economic benefits. Therefore, the output indicators in this study are divided into scientific and technological output and economic output. The number of valid inventions PATENT is adopted to

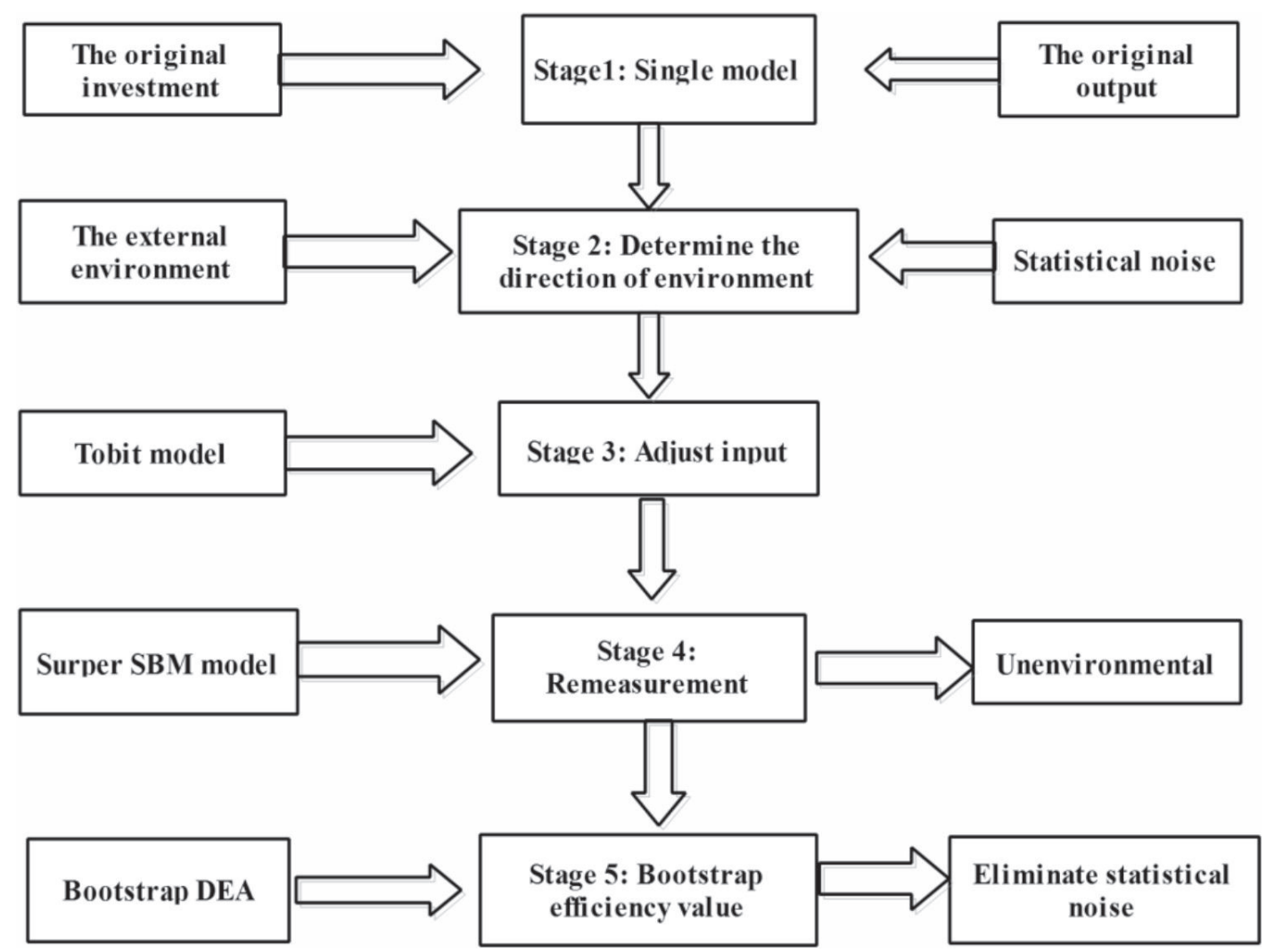

Fig. 2. Path diagram of the five-stage DEA model. 
Table 1. Input-output index system.

\begin{tabular}{|c|c|c|c|c|}
\hline $\begin{array}{c}\text { Target } \\
\text { classification }\end{array}$ & Level indicators & Secondary indicators & Unit & Symbol \\
\hline \multirow{5}{*}{$\begin{array}{l}\text { Input } \\
\text { indicators }\end{array}$} & \multirow{3}{*}{ Capital } & Internal expenditure of $R \& D$ expenditure & 10,000 yuan & IRDE \\
\hline & & Technology import outlay & 10,000 yuan & TIE \\
\hline & & Purchase of domestic technology expenditure & 10,000 yuan & DTE \\
\hline & Labour & Full-time equivalent of $R \& D$ personnel & person year & RDP \\
\hline & Land & Number of R\&D institutions & & NRDI \\
\hline \multirow{3}{*}{$\begin{array}{l}\text { Output } \\
\text { indicators }\end{array}$} & Output of science and technology & Number of valid invention patents & & PATENT \\
\hline & \multirow{2}{*}{ Economic output } & Main business income & $\begin{array}{l}100,000,000 \\
\text { yuan }\end{array}$ & INCOME \\
\hline & & Total profit & $\begin{array}{l}100,000,000 \\
\text { yuan }\end{array}$ & PROFIT \\
\hline \multirow{3}{*}{$\begin{array}{l}\text { Environmen- } \\
\text { tal variables }\end{array}$} & Macroeconomic level & GDP per capita & yuan & ANGDP \\
\hline & Labour market supply & $\begin{array}{c}\text { Number of students enrolled in higher } \\
\text { education per } 100,000 \text { population }\end{array}$ & people & EDU \\
\hline & Financial institution support & $\begin{array}{l}\text { Ratio of loan balance of financial institutions in } \\
\text { the banking industry to local GDP }\end{array}$ & ratio & LOAN \\
\hline
\end{tabular}

measure the scientific and technological output of strategic new and emerging enterprises because it better reflects the quality of the output of innovation activities. At the same time, total PROFIT is selected as the secondary index of economic output to reflect the actual benefits of innovation activities.

\section{Environmental Indicators}

As for the selection of indicators of environmental variables, the research results of Bao et al. and Qiao are referenced. [31-32] Environmental indicators are selected from three categories: macroeconomic level, labour supply, and financial support. In terms of the macro economy, Referring to the research results of Bao et al., per capita GDP (ANGDP) is selected as the secondary index. [33] Generally, a higher regional per capita GDP is more favourable for the development of strategic emerging industries. The development of strategic emerging industries cannot be separated from the support of high-quality human resources. In terms of the labour market, the number of students with higher education per 100,000 population (EDU) is therefore selected as the secondary index. In terms of financial support, the ratio of the loan balance of financial institutions in the banking industry and local GDP (LOAN) is selected as a secondary indicator. Strategic emerging industries are capital-intensive industries,

Table 2. Descriptive statistics of input-output and environmental data from 2011 to 2016.

\begin{tabular}{|c|c|c|c|c|c|}
\hline Variable & Number & Mean & Standard deviation & Minimum value & Maximum value \\
\hline RDP & 168 & 19336.73 & 36108.51 & 18.6 & 210298 \\
\hline DTE & 168 & 15438.93 & 52921.27 & 15 & 550664 \\
\hline NRDI & 168 & 173.3155 & 337.5385 & 1 & 1992 \\
\hline TIE & 168 & 656322.9 & 1274562 & 782 & 8406913 \\
\hline IRDE & 168 & 656322.9 & 1274562 & 782 & 8406913 \\
\hline INCOME & 168 & 4319.385 & 6968.697 & 16.9 & 37765.2 \\
\hline PROFIT & 168 & 273.119 & 403.2471 & 0 & 2094 \\
\hline PATENT & 168 & 4522.649 & 13790.69 & 2 & 117296 \\
\hline ANGDP & 168 & 50411.97 & 22496.67 & 16413 & 118198 \\
\hline EDU & 168 & 721.2474 & 543.0467 & 251.4405 & 3319.863 \\
\hline LOAN & 168 & 1.246769 & 0.4196663 & 0.412139 & 2.544447 \\
\hline
\end{tabular}


and the greater the financial institutions' support, the more conducive to industrial development. As shown in Table 1, the relevant indicator system of this study is constructed as follows.

\section{Data Selection of Model Variables}

Due to the short period of industrial development, there are no complete statistical datasets for strategic emerging industries in China. However, China's statistics on high-tech industries are relatively robust, and strategic emerging industries are based on the concept of high-tech industries. Therefore, it is feasible to replace the input-output data of strategic emerging industries with relevant data from the China High-tech Industry Statistical Yearbook. Based on the availability and continuity of data, the time span of the data in this study is from 2011 to 2016. In addition, the external environment data involved are from the China Financial Yearbook and China Statistical Yearbook.

Due to the serious lack of relevant data, the data of Tibet, Qinghai, and Gansu provinces as well as those of Hong Kong, Macao, and Taiwan are excluded. Descriptive statistics of samples are shown in Table 2.

Table 3. Statistics of technical innovation efficiency values measured by different models from 2011 to 2016.

\begin{tabular}{|c|c|c|c|c|c|c|c|c|c|c|}
\hline \multirow{2}{*}{$\begin{array}{c}\text { The serial } \\
\text { number }\end{array}$} & \multirow[b]{2}{*}{ DMU } & \multicolumn{3}{|c|}{2011} & \multicolumn{3}{|c|}{2012} & \multicolumn{3}{|c|}{2013} \\
\hline & & $\begin{array}{l}\text { Super } \\
\text { SBM }\end{array}$ & Four-stage & Five-stage & $\begin{array}{l}\text { Super } \\
\text { SBM }\end{array}$ & Four-stage & Five-stage & $\begin{array}{c}\text { Super } \\
\text { SBM }\end{array}$ & Four-stage & Five-stage \\
\hline 1 & Beijing & 1.01 & 0.78 & 0.84 & 1.2 & 0.7 & 0.9 & 1.01 & 0.66 & 0.86 \\
\hline 2 & Tianjin & 1.14 & 0.69 & 0.85 & 1.15 & 0.54 & 0.88 & 1.02 & 0.61 & 0.97 \\
\hline 3 & Hebei & 0.53 & 0.8 & 0.55 & 0.48 & 0.71 & 0.56 & 0.36 & 0.66 & 0.51 \\
\hline 4 & Liaoning & 1.02 & 0.48 & 0.36 & 0.76 & 0.46 & 0.37 & 0.44 & 0.42 & 0.38 \\
\hline 5 & Shanghai & 1.26 & 1.23 & 0.97 & 1.05 & 0.92 & 0.83 & 1.07 & 0.86 & 0.71 \\
\hline 6 & Jiangsu & 0.7 & 1.35 & 0.85 & 0.41 & 1 & 0.88 & 0.39 & 1.04 & 0.86 \\
\hline 7 & Zhejiang & 0.31 & 0.95 & 0.92 & 0.26 & 0.75 & 0.79 & 0.3 & 0.71 & 0.74 \\
\hline 8 & Fujian & 0.39 & 0.7 & 0.73 & 0.34 & 0.67 & 0.75 & 0.3 & 0.66 & 0.75 \\
\hline 9 & Shandong & 0.55 & 0.57 & 0.74 & 0.44 & 0.6 & 0.77 & 0.34 & 0.59 & 0.72 \\
\hline 10 & Guangdong & 1.95 & 1.16 & 0.85 & 1.48 & 1.1 & 0.88 & 1.05 & 1.13 & 0.85 \\
\hline 11 & Guangxi & 1.1 & 1.05 & 0.79 & 1.07 & 1 & 0.77 & 1.02 & 1 & 0.71 \\
\hline 12 & Hainan & 0.39 & 0.28 & 0.48 & 0.27 & 0.35 & 0.47 & 0.36 & 0.22 & 0.55 \\
\hline 13 & Shanxi & 1.01 & 0.33 & 0.52 & 1.03 & 0.89 & 0.76 & 0.56 & 0.3 & 0.47 \\
\hline 14 & Inner Mongolia & 1.2 & 1.56 & 0.63 & 1.52 & 1 & 0.7 & 1.08 & 1 & 0.7 \\
\hline 15 & Jilin & 1.06 & 0.85 & 0.82 & 1.13 & 1 & 0.8 & 1.04 & 1.02 & 0.73 \\
\hline 16 & Heilongjiang & 0.37 & 0.35 & 0.27 & 0.25 & 0.34 & 0.26 & 0.21 & 0.31 & 0.22 \\
\hline 17 & Anhui & 0.36 & 0.28 & 0.42 & 0.41 & 0.56 & 0.71 & 0.57 & 0.66 & 0.79 \\
\hline 18 & Jiangxi & 1.61 & 0.31 & 0.51 & 1.61 & 0.47 & 0.53 & 1 & 0.48 & 0.65 \\
\hline 19 & Henan & 1 & 1.06 & 0.78 & 1.24 & 1 & 0.76 & 1 & 1.01 & 0.75 \\
\hline 20 & Hubei & 0.56 & 0.28 & 0.78 & 0.45 & 0.22 & 0.68 & 0.34 & 0.21 & 0.68 \\
\hline 21 & Hunan & 0.64 & 0.63 & 0.68 & 0.44 & 0.63 & 0.65 & 0.43 & 0.31 & 0.46 \\
\hline 22 & Chongqing & 0.69 & 0.77 & 0.92 & 1.06 & 0.69 & 0.91 & 0.75 & 0.94 & 0.95 \\
\hline 23 & Sichuan & 1.07 & 1.06 & 0.88 & 0.56 & 1 & 0.95 & 0.52 & 0.53 & 0.82 \\
\hline 24 & Guizhou & 1.02 & 1.15 & 0.75 & 1.19 & 0.4 & 0.83 & 0.62 & 0.18 & 0.53 \\
\hline 25 & Yunnan & 1.11 & 0.42 & 0.63 & 1.14 & 0.3 & 0.7 & 1.01 & 1.03 & 0.85 \\
\hline 26 & Shaanxi & 0.37 & 0.56 & 0.55 & 0.26 & 0.53 & 0.53 & 0.26 & 0.54 & 0.57 \\
\hline 27 & Ningxia & 1.14 & 0.16 & 0.24 & 0.27 & 0.05 & 0.11 & 0.19 & 0.06 & 0.2 \\
\hline 28 & Xinjiang & 0.6 & 0.06 & 0.09 & 0.3 & 0.15 & 0.59 & 0.45 & 0.19 & 0.49 \\
\hline
\end{tabular}




\section{Results and Discussion}

Stage 1: Super SBM model measurement analysis considering environmental and statistical noise

Based on the data of 28 provinces in China from 2011 to 2016, the Super SBM four-stage DEA model and five-stage DEA model are used to calculate the technological innovation efficiency of China's strategic emerging industries (see Table 3).

As shown in Table 3, without excluding environmental and statistical noise, the original input-output data can be substituted into the Super
SBM model to calculate the technological innovation efficiency value of strategic emerging industries in 28 provinces of China $(\theta)$. Chronologically, the maximum and minimum values of $\theta$ in 2011 were 1.95 (Guangdong) and 0.31 (Zhejiang), respectively. In 2012, they were 1.61 (Jiangxi) and 0.25 (Heilongjiang), respectively. In 2013, they were 1.08 (Inner Mongolia) and 0.19 (Ningxia), respectively. In 2014, they were 1.61 (Jiangxi) and 0.2 (Shaanxi), respectively. In 2015, they were 1.09 (Shanghai) and 0.29 (Heilongjiang), respectively. In 2016, they were 2.13 (Jilin) and 0.3 (Shaanxi), respectively. In addition, from the perspective of the six-year efficiency mean of each province, Jilin

Table 3. Statistics of technical innovation efficiency measured by different models from 2011 to 2016.

\begin{tabular}{|c|c|c|c|c|c|c|c|c|c|c|c|c|c|}
\hline \multirow{2}{*}{$\begin{array}{c}\text { Serial } \\
\text { number }\end{array}$} & \multirow[b]{2}{*}{ DMU } & \multicolumn{3}{|c|}{2014} & \multicolumn{3}{|c|}{2015} & \multicolumn{3}{|c|}{2016} & \multicolumn{3}{|c|}{ 2011-2016 average } \\
\hline & & $\begin{array}{l}\text { Super } \\
\text { SBM }\end{array}$ & $\begin{array}{l}\text { Four- } \\
\text { stage }\end{array}$ & $\begin{array}{l}\text { Five- } \\
\text { stages }\end{array}$ & $\begin{array}{l}\text { Super } \\
\text { SBM }\end{array}$ & $\begin{array}{l}\text { Four- } \\
\text { stage }\end{array}$ & $\begin{array}{l}\text { Five- } \\
\text { stage }\end{array}$ & $\begin{array}{l}\text { Super } \\
\text { SBM }\end{array}$ & $\begin{array}{l}\text { Four- } \\
\text { stage }\end{array}$ & $\begin{array}{l}\text { Five- } \\
\text { stage }\end{array}$ & $\begin{array}{l}\text { Super } \\
\text { SBM }\end{array}$ & $\begin{array}{l}\text { Four- } \\
\text { stage }\end{array}$ & $\begin{array}{l}\text { Five- } \\
\text { stage }\end{array}$ \\
\hline 1 & Beijing & 1.45 & 0.62 & 0.87 & 1.07 & 0.52 & 0.77 & 1.08 & 0.54 & 0.8 & 1.12 & 0.64 & 0.84 \\
\hline 2 & Tianjin & 1.13 & 0.59 & 0.9 & 1.03 & 0.47 & 0.69 & 1.5 & 0.47 & 0.64 & 1.15 & 0.56 & 0.82 \\
\hline 3 & Hebei & 0.35 & 0.66 & 0.52 & 0.35 & 0.66 & 0.46 & 0.41 & 0.65 & 0.41 & 0.41 & 0.69 & 0.5 \\
\hline 4 & Liaoning & 0.51 & 0.48 & 0.42 & 0.81 & 0.5 & 0.46 & 0.91 & 0.56 & 0.66 & 0.74 & 0.48 & 0.44 \\
\hline 5 & Shanghai & 1.05 & 0.85 & 0.72 & 1.09 & 0.85 & 0.76 & 1.63 & 0.83 & 0.88 & 1.17 & 0.92 & 0.81 \\
\hline 6 & Jiangsu & 0.4 & 1 & 0.9 & 0.44 & 1.26 & 0.85 & 0.51 & 1 & 0.87 & 0.48 & 1.1 & 0.87 \\
\hline 7 & Zhejiang & 0.29 & 0.72 & 0.71 & 0.29 & 0.7 & 0.64 & 0.48 & 0.74 & 0.76 & 0.32 & 0.76 & 0.76 \\
\hline 8 & Fujian & 0.28 & 0.65 & 0.75 & 0.33 & 0.64 & 0.7 & 0.42 & 0.7 & 0.85 & 0.34 & 0.67 & 0.76 \\
\hline 9 & Shandong & 0.37 & 0.6 & 0.73 & 0.46 & 0.62 & 0.7 & 1.01 & 1 & 0.92 & 0.53 & 0.66 & 0.76 \\
\hline 10 & Guangdong & 1.21 & 1.2 & 0.9 & 1.06 & 1.28 & 0.94 & 1.04 & 1 & 0.88 & 1.28 & 1.15 & 0.88 \\
\hline 11 & Guangxi & 1 & 1 & 0.76 & 1 & 1.09 & 0.71 & 1.62 & 1 & 0.71 & 1.13 & 1.02 & 0.74 \\
\hline 12 & Hainan & 0.69 & 0.87 & 0.91 & 0.51 & 0.28 & 0.8 & 0.44 & 0.19 & 0.5 & 0.44 & 0.37 & 0.62 \\
\hline 13 & Shanxi & 1.04 & 1 & 0.81 & 1.01 & 0.7 & 0.83 & 1.13 & 0.34 & 0.45 & 0.96 & 0.59 & 0.64 \\
\hline 14 & Inner Mongolia & 1.59 & 1 & 0.78 & 0.37 & 0.13 & 0.18 & 0.39 & 0.1 & 0.15 & 1.01 & 0.8 & 0.52 \\
\hline 15 & Jilin & 1.56 & 1 & 0.8 & 1.02 & 1.04 & 0.73 & 2.13 & 0.69 & 0.63 & 1.31 & 0.93 & 0.75 \\
\hline 16 & Heilongjiang & 0.21 & 0.31 & 0.23 & 0.44 & 0.38 & 0.29 & 0.62 & 0.37 & 0.44 & 0.35 & 0.34 & 0.29 \\
\hline 17 & Anhui & 0.53 & 0.55 & 0.81 & 0.55 & 0.37 & 0.64 & 1.03 & 1 & 0.88 & 0.58 & 0.57 & 0.71 \\
\hline 18 & Jiangxi & 0.36 & 0.46 & 0.63 & 0.72 & 0.87 & 0.8 & 1.4 & 1 & 0.8 & 1.12 & 0.6 & 0.65 \\
\hline 19 & Henan & 0.61 & 1 & 0.78 & 1.08 & 1.08 & 0.75 & 0.7 & 1 & 0.79 & 0.93 & 1.02 & 0.77 \\
\hline 20 & Hubei & 0.45 & 0.22 & 0.7 & 0.51 & 0.25 & 0.73 & 1.01 & 0.31 & 0.98 & 0.55 & 0.25 & 0.76 \\
\hline 21 & Hunan & 0.43 & 0.3 & 0.61 & 0.37 & 0.27 & 0.46 & 1.01 & 0.47 & 0.74 & 0.55 & 0.44 & 0.6 \\
\hline 22 & Chongqing & 1.02 & 1 & 0.9 & 0.57 & 0.61 & 0.8 & 0.61 & 0.65 & 0.83 & 0.78 & 0.78 & 0.89 \\
\hline 23 & Sichuan & 0.62 & 1 & 0.97 & 0.62 & 0.42 & 0.72 & 1.03 & 0.67 & 0.92 & 0.74 & 0.78 & 0.88 \\
\hline 24 & Guizhou & 1.01 & 0.23 & 0.66 & 0.53 & 0.2 & 0.55 & 0.5 & 0.23 & 0.63 & 0.81 & 0.4 & 0.66 \\
\hline 25 & Yunnan & 0.59 & 0.23 & 0.54 & 1 & 1 & 0.88 & 0.51 & 0.34 & 0.7 & 0.89 & 0.55 & 0.72 \\
\hline 26 & Shaanxi & 0.2 & 0.55 & 0.58 & 0.3 & 0.56 & 0.57 & 0.3 & 0.62 & 0.63 & 0.28 & 0.56 & 0.57 \\
\hline 27 & Ningxia & 1.02 & 0.19 & 0.64 & 0.49 & 0.11 & 0.31 & 1.57 & 0.19 & 0.7 & 0.78 & 0.13 & 0.37 \\
\hline 28 & Xinjiang & 0.49 & 0.21 & 0.42 & 0.8 & 0.15 & 0.5 & 1 & 0.14 & 0.47 & 0.64 & 0.15 & 0.43 \\
\hline
\end{tabular}


Table 4. Tobit regression results.

\begin{tabular}{|c|c|c|c|c|c|c|c|c|c|c|}
\hline $\begin{array}{l}\text { Explanatory } \\
\text { variables }\end{array}$ & $\begin{array}{c}\text { RDP } \\
\text { (model 1) }\end{array}$ & Prob & $\begin{array}{c}\text { DTE } \\
\text { (model 2) }\end{array}$ & Prob & $\begin{array}{l}\text { NRDI } \\
\text { (model 3) }\end{array}$ & Prob & $\begin{array}{c}\text { TIE } \\
\text { (model 4) }\end{array}$ & Prob & $\begin{array}{l}\text { IRDE } \\
\text { (model 5) }\end{array}$ & Prob \\
\hline \multirow[b]{2}{*}{ Constant term } & 33867.41 & \multirow[b]{2}{*}{0.00} & 51473.10 & \multirow[b]{2}{*}{0.00} & 307.97 & \multirow[b]{2}{*}{0.00} & 1088468 & \multirow[b]{2}{*}{0.00} & 1177309 & \multirow[b]{2}{*}{0.00} \\
\hline & $\begin{array}{c}(18.35) * \\
* *\end{array}$ & & $\begin{array}{c}(18.16) * \\
* *\end{array}$ & & $(17.82) * * *$ & & $(19.03) * * *$ & & $\begin{array}{c}(17.96) * \\
* *\end{array}$ & \\
\hline \multirow{2}{*}{ ANGDP } & 0.68 & \multirow{2}{*}{0.00} & 0.61 & \multirow{2}{*}{0.00} & 0.01 & \multirow{2}{*}{0.00} & 23.00 & \multirow{2}{*}{0.00} & 24.79 & \multirow{2}{*}{0.00} \\
\hline & $(5.19) * * *$ & & $(3.04) * * *$ & & $(6.21) * * *$ & & $(5.45) * * *$ & & $(5.43) * * *$ & \\
\hline \multirow{2}{*}{ EDU } & \multirow{2}{*}{$\begin{array}{l}2.31 \\
(0.52)\end{array}$} & \multirow{2}{*}{0.28} & 7.39 & \multirow{2}{*}{0.18} & 0.03 & \multirow{2}{*}{0.50} & 312.35 & \multirow{2}{*}{0.03} & 156.34 & \multirow{2}{*}{0.35} \\
\hline & & & $(-1.09)$ & & $(-0.67)$ & & $(2.18) * *$ & & $(-1.01)$ & \\
\hline \multirow{2}{*}{ LOAN } & \multirow{2}{*}{$\begin{array}{c}11431.95 \\
(2.04)\end{array}$} & \multirow{2}{*}{0.31} & 8583.53 & \multirow{2}{*}{0.21} & 151.5292 & \multirow{2}{*}{0.00} & 347282.2 & \multirow{2}{*}{0.05} & 396697.6 & \multirow{2}{*}{0.04} \\
\hline & & & $(-1.01)$ & & $(2.98) * *$ & & $(1.93) *$ & & $(2.04) * *$ & \\
\hline $\begin{array}{l}\text { Logarithmic likeli- } \\
\text { hood ratio }\end{array}$ & 1990.66 & & 2060.98 & 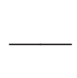 & 1201.02 & 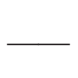 & 2573.629 & $\ldots$ & 2586.81 & \\
\hline
\end{tabular}

Note: $* * *$ and $* * *$ mean significant at the level of $10 \%, 5 \%$ and $1 \%$ respectively; Numbers in parentheses are the z-statistics.

is the largest, with an average of 1.31, and Ningxia is the smallest, with an average of 0.13 . This also indicates that compared with the classical BCC models, the Super SBM model can both distinguish the effectiveness of different efficiency values and order them.

\section{Stage 2: Tobit model used to eliminate environmental factors}

Due to the influence of external environmental factors, the efficiency value calculated by the Super SBM model does not objectively reflect the true efficiency of technological innovation in strategic emerging industries in different regions of China.

At the first stage, the result $\theta$ of the Super SBM model was selected as the dependent variable, and ANGDP, EDU and LOAN were selected as independent variables to build the panel Tobit model. Input slack is the input of various resources to achieve the goal of innovation. Therefore, the input slack can be taken as the opportunity cost of strategic emerging industries. If there is a positive correlation between the explanatory variable $\theta$ and the input slack variable, it means that the greater the input slack variable, the greater the opportunity cost, and the more detrimental to the improvement of technological innovation efficiency, and vice versa.

As shown in Table 4, according to the number of dependent variables, this study constructed five Tobit regression models (models 1-5). Specifically, the environmental variable per capita GDP (ANGDP) was significant at the 5\% level in all models, and ANGDP was positively correlated with all explained variables. This shows that GDP per capita has a significant impact on the original input slack variable of the DEA model. Due to the imbalance of economic development in different regions in China, the higher the GDP per capita in the region, the greater the impact on the input index. The number of higher education students per 100,000 population (EDU) has different influences on the input slack variable. EDU has a significant effect at the $5 \%$ level in model 4 only and has no significant effect in the other models. Finally, financial institution support (LOAN) is not significant in model 1 and model 2 , but significant in models 3,4 , and 5 at the levels of $5 \%, 10 \%$, and $5 \%$, respectively. This indicates that financial support has a significant impact on the number of R\&D institutions (NRDI), expenditure on technology introduction (TIE), and internal expenditure on R\&D expenditure (IRDE ), and the correlation is negative.

\section{Stages 3 and 4: Input variables adjusted and DEA value re-calculated}

The fitting value of the Tobit model in the second stage was used to re-adjust the input variable, and the adjusted input data and original output index were substituted into the Super SBM model to obtain the new technical innovation efficiency value (see Table 3 for details).

4.3.1 From Table 3 and Table 5, it can be seen that the efficiency mean obtained by the four-stage DEA method decreases in most regions after the removal of environmental factors. The efficiency values of 19 provinces and cities, including Beijing, Tianjin, Shanxi, Inner Mongolia, Liaoning, Jilin, Shanghai, Guangdong, and Guizhou, were lower than those before the adjustment, accounting for $64.29 \%$ of the total number of samples. The efficiency values of Hebei, Zhejiang, Jiangsu, Shandong, Fujian, Henan, Sichuan, and Shaanxi decreased by $0.04,0.09,0.13,0.28,0.28,0.33,0.44$, and 0.62 , respectively. Chongqing's efficiency value did not change. This indicates that the technical efficiency value measured by a single Super SBM model can be quite significantly affected by environmental factors, and a large number of favorable external environment 
Table 5. Changes in efficiency mean ranking.

\begin{tabular}{|c|c|c|c|c|c|c|c|c|c|}
\hline $\begin{array}{c}\text { Serial } \\
\text { number }\end{array}$ & $\begin{array}{l}\text { Provinces } \\
\text { (and cities) }\end{array}$ & $\begin{array}{l}\text { Super } \\
\text { SBM }\end{array}$ & $\begin{array}{l}\text { Ranking 1: } \\
\text { efficiency value }\end{array}$ & $\begin{array}{l}\text { Four- } \\
\text { stage }\end{array}$ & $\begin{array}{l}\text { Rank- } \\
\text { ing } 2\end{array}$ & $\begin{array}{c}\text { Changes after } \\
\text { adjustments }\end{array}$ & $\begin{array}{l}\text { Five- } \\
\text { stage }\end{array}$ & Ranking 3 & $\begin{array}{l}\text { Changes after } \\
\text { adjustments }\end{array}$ \\
\hline 1 & Beijing & 1.12 & 6 & 0.64 & 14 & $\downarrow$ & 0.84 & 5 & $\uparrow$ \\
\hline 2 & Tianjin & 1.15 & 4 & 0.56 & 18 & $\downarrow$ & 0.82 & 6 & $\downarrow$ \\
\hline 3 & Hebei & 0.41 & 24 & 0.69 & 11 & $\uparrow$ & 0.50 & 24 & - \\
\hline 4 & Liaoning & 0.96 & 9 & 0.59 & 16 & $\downarrow$ & 0.64 & 19 & $\downarrow$ \\
\hline 5 & Shanghai & 1.01 & 8 & 0.80 & 7 & $\uparrow$ & 0.52 & 23 & $\downarrow$ \\
\hline 6 & Jiangsu & 0.74 & 15 & 0.48 & 21 & $\downarrow$ & 0.44 & 25 & $\downarrow$ \\
\hline 7 & Zhejiang & 1.31 & 1 & 0.93 & 5 & $\downarrow$ & 0.75 & 13 & $\downarrow$ \\
\hline 8 & Fujian & 0.35 & 25 & 0.34 & 25 & $\downarrow$ & 0.29 & 28 & $\downarrow$ \\
\hline 9 & Shandong & 1.17 & 3 & 0.92 & 6 & $\downarrow$ & 0.81 & 7 & $\downarrow$ \\
\hline 10 & Guangdong & 0.48 & 22 & 1.10 & 2 & $\uparrow$ & 0.87 & 4 & $\uparrow$ \\
\hline 11 & Guangxi & 0.32 & 27 & 0.76 & 10 & $\uparrow$ & 0.76 & 10 & $\uparrow$ \\
\hline 12 & Hainan & 0.58 & 18 & 0.57 & 17 & $\uparrow$ & 0.71 & 16 & $\uparrow$ \\
\hline 13 & Shanxi & 0.34 & 26 & 0.67 & 12 & $\uparrow$ & 0.76 & 12 & $\uparrow$ \\
\hline 14 & Inner Mongolia & 1.12 & 7 & 0.60 & 15 & $\downarrow$ & 0.65 & 18 & $\downarrow$ \\
\hline 15 & Jilin & 0.53 & 21 & 0.66 & 13 & $\uparrow$ & 0.76 & 9 & $\uparrow$ \\
\hline 16 & Heilongjiang & 0.93 & 10 & 1.02 & 3 & $\uparrow$ & 0.77 & 8 & $\uparrow$ \\
\hline 17 & Anhui & 0.55 & 19 & 0.25 & 26 & $\downarrow$ & 0.76 & 11 & $\uparrow$ \\
\hline 18 & Jiangxi & 0.55 & 20 & 0.44 & 22 & $\downarrow$ & 0.60 & 21 & $\downarrow$ \\
\hline 19 & Henan & 1.28 & 2 & 1.15 & 1 & $\uparrow$ & 0.88 & 2 & - \\
\hline 20 & Hubei & 1.13 & 5 & 1.02 & 4 & $\uparrow$ & 0.74 & 14 & $\downarrow$ \\
\hline 21 & Hunan & 0.44 & 23 & 0.37 & 24 & $\downarrow$ & 0.62 & 20 & $\uparrow$ \\
\hline 22 & Chongqing & 0.78 & 13 & 0.78 & 9 & $\uparrow$ & 0.89 & 1 & $\uparrow$ \\
\hline 23 & Sichuan & 0.74 & 16 & 0.78 & 8 & $\uparrow$ & 0.88 & 3 & $\uparrow$ \\
\hline 24 & Guizhou & 0.81 & 12 & 0.40 & 23 & $\downarrow$ & 0.66 & 17 & $\downarrow$ \\
\hline 25 & Yunnan & 0.89 & 11 & 0.55 & 20 & $\downarrow$ & 0.72 & 15 & $\downarrow$ \\
\hline 26 & Shaanxi & 0.28 & 28 & 0.56 & 19 & $\uparrow$ & 0.57 & 22 & $\uparrow$ \\
\hline 27 & Ningxia & 0.78 & 14 & 0.13 & 28 & $\downarrow$ & 0.37 & 27 & $\downarrow$ \\
\hline 28 & Xinjiang & 0.64 & 17 & 0.15 & 27 & $\downarrow$ & 0.43 & 26 & $\downarrow$ \\
\hline
\end{tabular}

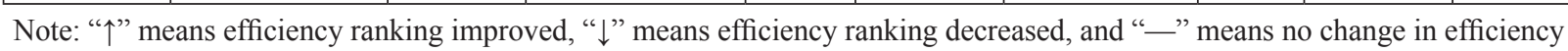
ranking

factors "falsely" increases the technical efficiency value of many provinces.

From the ranking perspective, the efficiency mean of the four-stage DEA model excluding environmental factors dropped in 15 provinces and rose in 14 provinces. From the progress perspective, Jiangsu, Zhejiang, and Fujian saw the largest rise in the ranking, with the ranking of the sample improving from 22, 27, and 26 to 2, 10, and 12, respectively. Ningxia, Guizhou, and Xinjiang saw the biggest declines, dropping by 14, 11, and 10 places, respectively. Compared with the original calculation results, the adjusted efficiency value is more consistent with reality. This shows that if external environmental factors are not controlled, it is difficult for the classical DEA model to reflect the real efficiency values of some provinces.

\section{Stage 5: Bootstrapped model}

Table 3 reflects the revised bootstrapped DEA model results. The statistics show that in further correcting the four-stage DEA model, the five-stage model innovates in two ways. First, it further optimizes the overall distribution of the 28 provincial efficiency values. 
The adjusted standard deviation of efficiency value is 0.16 in the five-stage model and 0.6 in the four-stage. Therefore, the standard deviation has been reduced by 0.44 . Second, the five-stage model measurement shows that the average technological innovation efficiency value of 28 provinces from 2011 to 2016 is less than 1 , which is highly consistent with the characteristics of strategic emerging industries in the early stages of development.

In addition, the efficiency value optimization of the five-stage DEA model can be further reflected in Table 5. For example, the efficiency means measured by the single DEA method include: 0.48 for Jiangsu, ranking $22^{\text {nd }} ; 0.32$ for Zhejiang, ranking $27^{\text {th }} ; 0.34$ for Fujian, ranking $26^{\text {th }}$; and 0.81 for Guizhou, ranking 12th, which are inconsistent with reality. The results measured by the five-stage DEA model are: 0.87 for Jiangsu, ranking 4th; 0.76 for Zhejiang, ranking $10^{\text {th }}$; 0.76 for Fujian, ranking 12th; and 0.66 for Guizhou, ranking 17 th. Likewise, the results measured by the four-stage DEA model include 0.64 for Beijing, ranking 14th, and 0.56 for Tianjin, ranking 18th. This method lowers the values as well as the rankings of the two cities. In contrast, the efficiency means of Beijing and Tianjin adjusted by the five-stage model are 0.84 , ranking $5^{\text {th }}$, and 0.82 , ranking $6^{\text {th }}$, respectively. It shows that the bootstrapped model with self-sampling repeated 1,000 times can effectively eliminate random errors and deliver more stable results. As shown in Fig. 2, the result curve of the five-stage model eliminates the outliers, and the result is more stable compared with the other two models after eliminating environmental factors and random errors.

To summarize, there are significant deviations in the results for all versions of the DEA model from singleto four-stage, and the five-stage DEA model constructed in this study can provide more accurate results.

Finally, as shown in Fig. 3, the results measured by the four-stage DEA and Super SBM models reveal that differences in provincial technological innovation efficiency show a "U-shaped" fluctuation. After the elimination of environmental factors and statistical deviation, however, the five-stage DEA model results remain relatively stable. The results show that 1) environmental factors and statistical deviation do have a significant effect on technological innovation efficiency; and 2) the technological innovation efficiency of strategic emerging industries is significantly affected by external environmental factors such as economic development, labour supply, and financial policy. To develop strategic emerging industries, it is necessary to consider the fact that the industry is at the initial stage. To promote industrial innovation, it is crucial to create environmental factors conducive to industrial development.

\section{Comparison of Different Models Based on Regions}

As shown in Table 6, the technological innovation efficiency of strategic emerging industries in the three regions of China (Eastern, Central, and Western) showed a "U-shaped" fluctuation from 2011 to 2016. Comparing the average technological innovation efficiency of the three regions, the result calculated by the single Super SBM is East $>$ Middle $>$ West. With the effects of environmental factors and random errors removed, the results of the five-stage model show that: the Eastern region is the highest (0.57), the Western is second (0.56), and the Central is lowest (0.53). Nationally, the efficiency means of the Super SBM, four-stage model, and five-stage model measurements are $0.78,0.60$, and 0.55 , respectively. The contribution of environmental factors to the average technology innovation efficiency is 0.18 , and of statistical noise, 0.05. From the perspective of the Eastern region, the contribution of external environmental factors to the average efficiency of technological innovation is 0.17 , with a contribution rate of $21 \%$, and of statistical noise 0.08 , with an impact rate of $9.9 \%$.

This reveals that the development of China's strategic emerging industries is significantly affected by external policies, the economy, and other macro environmental factors, and the government's support and cultivation of strategic emerging industries have a significant impact on promoting industrial innovation. At the same time, if the environmental factors and statistical errors are excluded, industrial innovation in the Eastern, Central

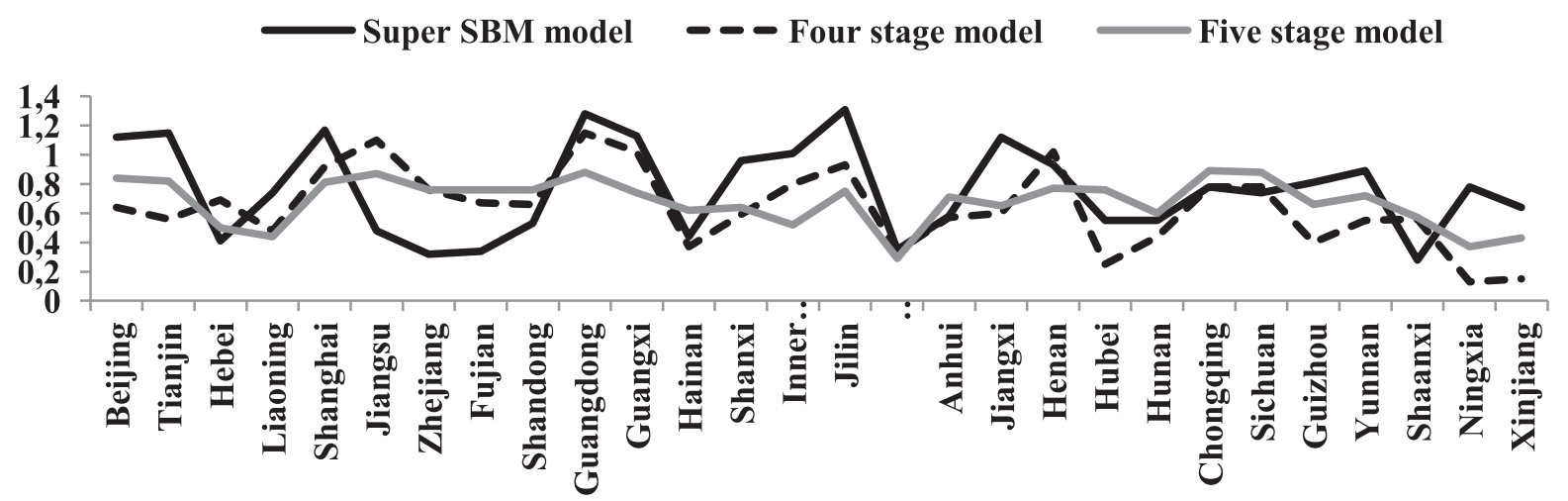

Fig. 3. Comparison of efficiency means by different models. 
Table 6. Comparison of efficiency means of different regions.

\begin{tabular}{|c|c|c|c|c|c|c|c|c|}
\hline Area & Model & 2011 & 2012 & 2013 & 2014 & 2015 & 2016 & Mean \\
\hline \multirow{3}{*}{$\begin{array}{l}\text { Eastern } \\
\text { region }\end{array}$} & Super SBM & 0.86 & 0.78 & 0.82 & 0.73 & 0.73 & 0.92 & 0.81 \\
\hline & Four-stage & 0.74 & 0.63 & 0.61 & 0.67 & 0.64 & 0.62 & 0.65 \\
\hline & Five-stage & 0.54 & 0.57 & 0.58 & 0.56 & 0.51 & 0.66 & 0.57 \\
\hline \multirow{3}{*}{$\begin{array}{l}\text { Central } \\
\text { region }\end{array}$} & Super SBM & 0.87 & 0.86 & 0.68 & 0.75 & 0.66 & 0.98 & 0.80 \\
\hline & Four-stage & 0.63 & 0.68 & 0.59 & 0.65 & 0.57 & 0.59 & 0.62 \\
\hline & Five-stage & 0.50 & 0.55 & 0.51 & 0.58 & 0.50 & 0.55 & 0.53 \\
\hline \multirow{3}{*}{$\begin{array}{l}\text { Western } \\
\text { region }\end{array}$} & Super SBM & 0.86 & 0.78 & 0.64 & 0.71 & 0.64 & 0.79 & 0.74 \\
\hline & Four-stage & 0.60 & 0.55 & 0.59 & 0.59 & 0.44 & 0.41 & 0.53 \\
\hline & Five-stage & 0.58 & 0.56 & 0.53 & 0.52 & 0.55 & 0.60 & 0.56 \\
\hline \multirow{3}{*}{ National } & Super SBM & 0.86 & 0.81 & 0.71 & 0.73 & 0.68 & 0.90 & 0.78 \\
\hline & Four-stage & 0.65 & 0.62 & 0.60 & 0.64 & 0.55 & 0.54 & 0.60 \\
\hline & Five-stage & 0.54 & 0.56 & 0.54 & 0.55 & 0.52 & 0.60 & 0.55 \\
\hline
\end{tabular}

and Western regions is not significantly different. This also indicates that to accurately measure the value of industrial technological innovation, it is necessary to consider different industries in the same environment. Finally, according to the calculation of the five-stage DEA model, the actual technological innovation efficiency of China's strategic emerging industries is lower than 0.6 , and there is a large redundancy in resource allocation. Therefore, to further improve productivity by advanced technology is important to the promotion of industrial development.

\section{Conclusions}

The classical single DEA model has the disadvantage of ignoring environmental influence and statistical noise. The mainstream four-stage DEA model based on the BCC-Tobit-BCC paradigm involves technical inefficiencies and is unable to deal with endogeneity due to the BCC model. To focus on the environmental factors affecting technological innovation in strategic emerging industries and reduce statistical noise, this study constructed a five-stage model combining the Super SBM-Tobit-Super SBM model and Bootstrap DEA. In order to verify the effectiveness of the model, this study empirically measured the technical efficiency of strategic emerging industries in 28 provinces and cities by using statistical yearbook data from 2011 to 2016. It finds the following:

(1) The technology innovation efficiency of strategic emerging industries in 28 provincial regions of China is insufficient after environmental factors and statistical noise are eliminated using the five-stage model. The highest average efficiency is that of Chongqing at 0.89 , followed by Guangdong at 0.88 , and the lowest is that of Heilongjiang at 0.29 . This indicates that there is significant redundancy in investment in technological innovation in China's strategic emerging industries, and efficiency must be improved.

(2) When measuring the technological innovation efficiency of strategic emerging industries, there are significant differences among the single DEA method, the four-stage DEA method, and the five-stage DEA method. Without eliminating environmental factors and statistical errors, technical innovation efficiency is overestimated and does not objectively reflect the reasons for lack of innovation. The five-stage DEA model constructed in this study not only absorbs the advantages of the four-stage DEA model in "flattening" environmental interference, but also avoids the impact of random factors. The five-stage DEA model can avoid the emergence of outliers.

(3) After eliminating the environmental factors and statistical noise, the technological innovation efficiency of China's strategic emerging industries shows a "U-shaped" fluctuation in three regions, with the highest in the Eastern (0.57), the medium in the Western (0.56), and the lowest in the Central region (0.53).

(4) A comparison between the results of the five-stage DEA model and other models shows that environmental factors have a significant impact on China's strategic emerging industries. If environmental factors are excluded in different regions, the innovation efficiency of enterprises in strategic emerging industries will turn out to be the same, which is in line with development characteristics at the initial stage of China's strategic emerging industries. Therefore, the government can significantly promote innovation-driven development through funds, policies and the creation of high-quality financial services environments.

In order to promote the improvement of technological innovation efficiency of strategic emerging industries, 
it is necessary for government departments to provide financial subsidies to strategic emerging industries at the embryonic stage. At the same time, tax incentives and lowering the threshold will also benefit to support R\&D activities in strategic emerging industries. Finally, Banks and other credit departments are necessary to design diversified financing products which will promote the innovative development of strategic emerging industries.

\section{Acknowledgements}

This research was funded by Tianjin Philosophy and Social Science Planning Project (No. TJGLQN19XSX-006), by Central University Basic Scientific Research Operating Expenses Project of Civil Aviation University of China Special Project (No.3122019012).

\section{Conflict of Interest}

The authors declare no conflict of interest.

\section{References}

1. AFRIAT S.N. Efficiency Estimation of Production Function, International Economic Review, 13 (3), 568, 1972.

2. AIGNER D., LOVELL C.A., SCHMIDT P. Formulation and estimation of stochastic frontier production function models, Journal of Econometrics, 6 (1), 21, 1977.

3. SONG G., XU Y. The technical efficiency of SMEs based on SFA, Systems Engineering, 31 (2), 77, 2013.

4. WANG X., JIANG Z., ZHENG Y. Analysis on dynamic evolution and discernment of of innovation efficiency in china's universities: based on nonparametric kernel density estimation and SFA model. Statistics \& Information Forum. 33 (9), 81, 2018.

5. CHARNES A., COOPER W.W., RHODES E. Measuring the efficiency of decision make units. European Journal of Operational Research, 6 (2), 429, 1978.

6. LI H., HE F., DENG F. How does Environmental Regulation Promote Technological Innovation and Green Development? New Evidence from China. Polish Journal of Environmental Studies, 29 (1), 689, 2020.

7. SHEN N., ZHOU J., ZOU W. Energy efficiency measures and convergence in China, Taking into account the effects of environmental and random factors. Polish Journal of Environmental Studies, 24, 257, 2015.

8. SU K., CHEN Y. An empirical study on ecological efficiency and influencing factors of industrial enterprises in Fujian province, China. Polish Journal of Environmental Studies, 28 (6), 4381, 2019.

9. LIU Y.Q., QUAN Q., ZHU J.L., W H. Green Technology Innovation, Industrial Agglomeration and Ecological Efficiency: A Case Study of Urban Agglomerations on Yangtze River Economic Belt. Resources and Environment in the Yangtze Basin, 27 (11), 2395, 2018.

10. TEIRLINCK P., KHOSHNEVIS P. Within-cluster determinants of output efficiency of R\&D in the space industry. Omega-international journal of management science, 94 (7), 1, 2020.

11. SHIN J., KIM C., YANG H. Does Reduction of Material and Energy Consumption Affect to Innovation Efficiency? The Case of Manufacturing Industry in South Korea. Energies, 1178 (12), 1, 2019

12. LEE J., KIM C., CHOI G. Exploring data envelopment analysis for measuring collaborated innovation efficiency of small and medium-sized enterprises in Korea. European journal of operational research, 278 (2), 533, 2019.

13. CHEN Y., CHEN J., JI C. A comparison of the technical innovation efficiency of different types of enterprises in China. Science Research Management, 39 (5), 1, 2018.

14. BAO Y., LU R., XIONG L. Study on Innovation Efficiency of China's LCD Industry Based on Two-Stage DEA Model. Science of science and management of S. \& T, 397 (5), 49, 2016.

15. QU G., SONG L., GUO Y. Research on technological innovation efficiency of Chinese listed companies: based on three-stage DEA method. Macroeconomic research, 235 (5), 972018.

16. LIAO M., CAO X. The empirical study of China's provincial synergy innovation efficiency, Systems Engineering. 35 (9), 45, 2017.

17. FRIED H.O., SCHMIDT S.S., YAISAWARNG S. Incorporating the Operating Environment into a Nonparametric Measure of Technical Efficiency. Journal of the Productivity Analysis, 12 (3), 249, 1999.

18. FRIED H.O., LOVELL C., SCHMIDT S., YAISAWARNG S. Accounting for Environment Effects and Statistical Noise in Data Envelopment Analysis. Journal of Productivity Analysis, 17 (1), 157, 2002.

19. CHEN K., WANG S. Improvement of three-stage combined efficiency measurement model with environmental impact and its application in R\&D efficiency measurement. Systems Engineering Theory \& Practice, 34 (7), 1811, 2014.

20. FAN D., WANG W. Total factor energy efficiency of Chinese provincial industry: based on four-stage DEA and Bootstrapped DEA. Systems Engineering, 31 (8), 72, 2013.

21. CHEN C., SHENG G. Measurement and analysis of technical efficiency of agricultural production in China's provinces - an empirical study based on four-stage DEA and Bootstrapped DEA. Science \& Technology Progress and Policy, 31 (3), 50, 2014.

22. ZHAO J., YANG W. Measurement of green development efficiency in various regions of China. Statistics \& Decision, 27 (29), 115, 2017.

23. YU M., SUN J. Government support and production efficiency of China's new energy vehicle industry - an empirical analysis based on the four-stage DEA model. East China Economic Management, 32 (7), 48, 2018.

24. TONE K. Slacks-based Measure of Efficiency in Data Envelopment Analysis. European Journal of Operational Research, 130 (3), 498, 2001.

25. TONE K. A slacks-based measure of super-efficiency in data envelopment analysis, European Journal of Operational Research, 143 (1), 32, 2002.

26. YE S., WANG H. Discussion on the homogeneity of decision make units in the multi-stage DEA model. Statistics \& Information Forum, 27 (2), 15, 2012.

27. KNIEP A., SIMAR L., WILSON P. Asymptotics and Consistent Bootstraps for DEA Estimators in Nonparametric Frontier Models. Econometric Theory, 24 (6), 1663, 2008. 
28. SIMAR L., WILSON R. Statistical Inference in Nonparametric Models: The State of The Art. Journal of Productivity Analysis, 13, 49, 2000.

29. LIU H., LIU Y., QIAO H., HU Y. Research on technological innovation efficiency of China's strategic emerging industries, Systems Engineering-Theory \& Practice, 35 (9), 2296, 2015.

30. SUN Z., SONG W. Evaluation of independent innovation capability of strategic emerging industries: establishment of industrial innovation index system with enterprises as the main body, Economic Management Journal, 34 (8), 20, 2012.
31. QIAO Y. Evaluation of provincial innovation efficiency in China based on three-stage DEA-windows analysis, Science of Science and Management of S \& T, 38 (1), 88, 2017.

32. DRAGANA N., HRISTINA S., DRAZENKO B., LJILJANA S., PREDRAG L., ZELJKA S., OLIVERA K. Using Material Flow Analysis for Waste Management Planning. Polish Journal of Environmental Studies, 28 (1), $255,2019$.

33. BAO Y., LI Y., XIAO T. Research on technical efficiency and spatial distribution of high-tech industries in China's provincial regions, Fujian Tribune, 7, 168, 2018. 
